\title{
AMELIORATIVE EFFECT OF TOCOPHERYL ACETATE IN LUNG OF CIGARETTE SMOKE EXPOSED ADULT SWISS ALBINO MICE
}

\author{
Janardan Chaudhary ${ }^{1}$, Royana Singh ${ }^{1 *}$, S N Shamal ${ }^{1}$, K Supriya ${ }^{1}$, Mona Srivastava ${ }^{2}$ and RS \\ More $^{1}$ \\ ${ }^{1}$ Department of Anatomy, Institute of Medical Sciences, Banaras Hindu University, Vanarasi, Uttar Pradesh- \\ 210055, India. \\ ${ }^{2}$ Department of Psychiatry, Institute of Medical Sciences, Banaras Hindu University, Vanarasi, Uttar \\ Pradesh-210055, India.
}

\begin{abstract}
Lung is the one of the first organ to metabolise the cigarette smoke contents soon after inhalation. Adult male mice were assigned to six different groups different groups (Group I (control), Group II (Tocopheryl acetate), Group III (soyabean oil used as vehicle for Tocopheryl acetate), Group IV (Cigarette smoke Exposed), Group V (Cigarette smoke exposed plus Tocopheryl acetate) and Group VI(Cigarette smoke exposed plus soyabean oil) were exposed to cigarette smoke 3 times a day for 20 minutes each time for 28 days and Tocopheryl acetate with dose of $200 \mathrm{mg} / \mathrm{kg} / \mathrm{day}$ in $0.3 \mathrm{ml}$ of soyabean oil as vehicle orally through oral gavage. Cigarette smoke exposed lung appreciated highly in pathogenicby lymphatic nodular around hyperplasia bronchus collapsed alveolar sac, inflammatory interalveolar septum. Lung of cigarette smoke exposed group showed significantly increased oxidant level as malondialdehyde $815.2 \pm 54.62 \mu \mathrm{mol} / \mathrm{mg}$ protein (Group V) and $823.5 \pm 68.17 \mu \mathrm{mol} / \mathrm{mg}$ protein (Group $\mathrm{VI}$ ). Tocopheryl acetate administrated to cigarette smoke exposed lung(Group V) markedly reduced the severity of the pathogenesis and oxidant level $(570.5 \pm 56.32 \mu \mathrm{mol} / \mathrm{mg}$ protein). Present study, tocopheryl acetate thought to be as a protective agent against cigarette smoke.
\end{abstract}

Keywords : Reactive oxygen species; Emphysematous lung; Antioxidant

\section{INTRODUCTION}

As per World Health Organisation Report on the Global Tobacco Epidemic 2015, 1 billion to 2.8 billion i.e. One quarter of world's population use tobacco and cigarette smoking at present ${ }^{1}$. Cigarette smoking occurred among adults in the United States about $18 \%$ in 2012 . Nearly $80 \%$ of the more than 1 billion smokers worldwide live in low- and middle-income countries. The chemical compositions of mainstream and sidestream of cigarette smoke and measurements in spaces where smoking occurs indicate that exposure to environmental tobacco smoke will result in exposure to toxic and carcinogenic agents ${ }^{2}$. Cigarette smoke has been calculated to contain $10^{17}$ oxidant molecules/puff, of which $10^{14}$ are reactive oxygen species (ROS) ${ }^{3}$. The gas phase of cigarette smoke mainly contains short lived ROS, such as superoxide radical and nitrogen oxide, both of which immediately react to form highly reactive peroxynitrite. In contrast, the tar phase contains the long lived hydroquinones that undergo redox-cycle to form superoxide radical and hydrogen peroxide via semiquinones, thereby

*Corresponding author:

Email: drroyanasingh@gmail.com

http://dx.doi.org/10.20530/IJTA 34 11-16

ISSN 2320-138X () 2016 resulting in persistent oxidative stress ${ }^{4}$. Cigarette smoke induced activation of inflammatory cells may also contribute to enhanced oxidant production in tissues ${ }^{5}$. Lung is the first and the most frequent vital organ to counter cigarette smoke contents and metabolise in active and passive smokers. Cigarette smoking yields chemical substances with cytotoxic potentials. These chemicals created by smoking induce oxidative stress associated with lipid peroxidation 6 . Besides these direct mechanisms of enhanced oxidative stress, cigarette smoke also increases oxidative stress in the lungs by recruiting and activating phagocytes to release ROS ${ }^{7}$.

Tocopheryl acetate is Vitamin E acetate subsequently proved to be effective in preventing lipid peroxidation and other radical driven oxidative events ${ }^{8-9}$. Aim of the present study to whether tocopheryl acetate would be able to reduce the oxidative stress and prevent from the lung damage of cigarette smoke exposed Swiss albino mice.

\section{MATERIALS and METHODS}

The present study was conducted in the Department of Anatomy, Institute of Medical Sciences, Banaras Hindu University, Varanasi221005, India. Adult Swiss albino mice with an average weight and age about 20-30 gm and 60-90 days old respectively were used in the present 
study. For using these animals, the consent with reference Dean/2015/CAEC/991 was taken from institutional ethical committee of Banaras Hindu University, Varanasi.

\section{Procurement and Acclimatization of Animals}

Swiss albino mice were procured from the animal house of Department of Anatomy, Institutes of Medical Sciences, Banaras Hindu University. They were reared in polypropylene cage $(25 \times 20 \times 15 \mathrm{~cm})$ under standard laboratory

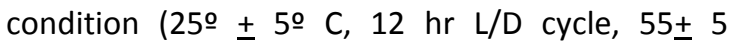
Relative Humidity) 2 weeks proper acclimatization. Dry rice bran was used as a bedding material. They were fed pelleted diet obtained from animal feed supply center, Varanasi and tap water ad libitum.

\section{Cigarette Smoking System}

To assume environmental tobacco smoke i.e. main stream/ side stream smoke for experimental mice, cigarette smoking system (CSS) protocol was modified from the exposure protocol of Santiago et al. 2009 in order to expose cigarette smoke which contained of three parts.

Air generator: Air Generator was meant for generation of air inside the chamber and aeration to the smoke chamber through a $25 \mathrm{~cm}$ long wind pipe. It had six walls with dimension of $15 \times 10 \times 10$ $\mathrm{cm}$. Air cool fan with $6 \mathrm{~cm}$ diameter consisting of 11 leaflets, 5V DC, $50 \mathrm{~mA}$ adaptor motor was fixed on one of the wall was fixed. Opposite to this wall, a $25 \mathrm{~cm}$ long wind pipe was fixed to connect the pipe to smoke chamber.

Smoke chamber: Smoke Chamber was meant for accumulation of cigarette smoke produced from cigarette sticks. This chamber consisted of six walls with dimension of $20 \times 10 \times 10 \mathrm{~cm}$. It consisted of an open/close able door $(12 \times 10 \mathrm{~cm})$ through which, cigarettes were taken in and out of the chamber. It had two holes; one hole on wall facing towards to air generator to receive the wind pipe from air generator and another hole on its roof to fix a 60 $\mathrm{cm}$ long wind pipe which connected to inhalation chamber. It also contained a cigarette stand which was used to stand burning cigarettes.

Inhalation chamber: Inhalation Chamber was meant for cigarette exposure of mice with dimension of $50 \times 25 \times 20 \mathrm{~cm}$. It consisted of six walls on which an acrylic sheet was fixed on an open wall $(40 \mathrm{x} 13 \mathrm{~cm})$ to observe the behavioural activities of mice during their exposure. Roof was open/close able by two shutters to allow the smoke vapour out and to keep mice in/out of the chamber. A $60 \mathrm{~cm}$ long wind pipe was passed through a wall facing towards the smoke chamber to receive cigarette smoke from smoke chamber.

\section{Experimental design}

Seventy two mice were taken in the present study and randomly assigned into 6 groups. Each group contained twelve mice were as following; Group I: Control (given equivalent amount of distilled water), Group II: Treated with tocopheryl acetate $(200 \mathrm{mg} / \mathrm{kg}$ body weight), Group III: Treated with soybean oil group (given $0.3 \mathrm{ml}$ of soya bean oil once a day), Group IV: Cigarette smoke exposed(thrice a day for one hour each time twenty minutes), Group V: With combined Cigarette smoke expose and tocopheryl acetate (dose mentioned above), Group VI: With combined Cigarette smoke expose and soya bean oil (dose mentioned above).

\section{Sacrifice of the mice}

According to experimental protocol for drug and cigarettes smoke expose, $50 \%$ of drug treated and control mice of each group were sacrificed by cervical dislocation on $29^{\text {th }}$ day morning of cigarette smoke expose for histological observation and biochemical study. $50 \%$ of treated and control were subjected for neurobehavioral test(not reported in article)

Tissue collection and preparation for histological observation

Immediately after cervical dislocation, lung was taken by midline incision in thorax. Thus obtained lung was fixed in $10 \%$ formaldehyde solution at least for a week. Dehydration was achieved by passing tissues through a graded series of alcohol followed by two changes of xylene. After infiltration in paraffin wax, tissues were embedded in pure paraffin wax.

Sections of about $6 \mu \mathrm{m}$ thick were obtained by a microtome (Weswox) and mounted on glass slides stained with Hematoxylin and eosin (H\&E) and mallory trichome (MT)stains were done for histological observation. The prepared sections were examined and photographed using Leica microscope equipped with digital camera. H\&E, PAS and MT stains were done for histological observation.

Tissue collection and preparation for Biochemical study on oxidative stress

Immediately after cervical dislocation, thorax was exteriorized by mid line incision. Adequate quantity of lung tissues was autopsied, kept in phosphate buffer solution (PBS) at $-20^{\circ} \mathrm{C}$ and $10 \%(\mathrm{w} / \mathrm{v})$ tissues was homogenated in ice cold 
$\operatorname{PBS}(0.1 \mathrm{M}, \mathrm{pH}$ 7.4). The homogenate was centrifuged and the resulting supernatant was used for the biochemical parameters to test the oxidative stress.

\section{Estimation of malondialdehyde (MDA) level}

MDA was estimated by thiobarbituric acid test protocol from Devasagayam ${ }^{10}$ et al., 2003 at 530 $\mathrm{nm}$ by ELICO- SL-104 double beam UL-UV Spectrophotometer.12

\section{Statistical analysis}

All data were entered into excel sheet and mean and standard deviation (S.D.) were calculated. One way ANOVA, post hoc analysis, followed by bonferroni test was done using software Graph Pad Prism 6.0. If it was significant, multiple comparison test was used for post hoc analysis in order to compare control and treated groups. $\mathrm{P}<0.05$ was considered as significant and $\mathrm{P}<0.0001$ was considered as highly significant.

\section{RESULTS}

\section{Gross features of adult mice lung}

Cigarette smoke expose groups IV and VI (CSE and CSE plus soyabean oil) showed emphysematous lung with rough surface and multiple hematoma (fig.1). In administration of tocopheryl acetate to cigarette smoke expose group V (CSE plus tocopheryl acetate treated mice) showed glossy surface with few hematoma in lung.Group I, II and III (Control, tocopheryl acetate and soya bean oil treated mice respectively) showed normal features with glossy surface lung (fig 1).

Histopathological examaniation of adult mice lung

In cigarette smoke exposed groups IV and VI (CSE and CSE plus soya bean oil treated mice respectively), bronchus was hyperplasia lined by shedded respiratory epithelium (fig.1). Abundantly, mucin accumulation on the shedded epithelial lining was observed. Mallory trichome stain showed markedly fibre with thicken wall (fig.1). There was presence of lymphatic nodules entirely around bronchus. Alveoli sac showed collapsed with inflammatory cell infiltration. MT stain showed markedly presence of fibre in parenchyma of the lung (fig.1).

In administration of tocopheryl acetate to cigarette smoke expose group V (CSE plus tocopheryl acetate treated mice), few mucin accumulation, lymphatic infiltration, alveoli collapse, apoptotic cells and fibre were observed in MT stain but amount and severity were seemed to be reduced incompare to group IV and VI (fig.1).

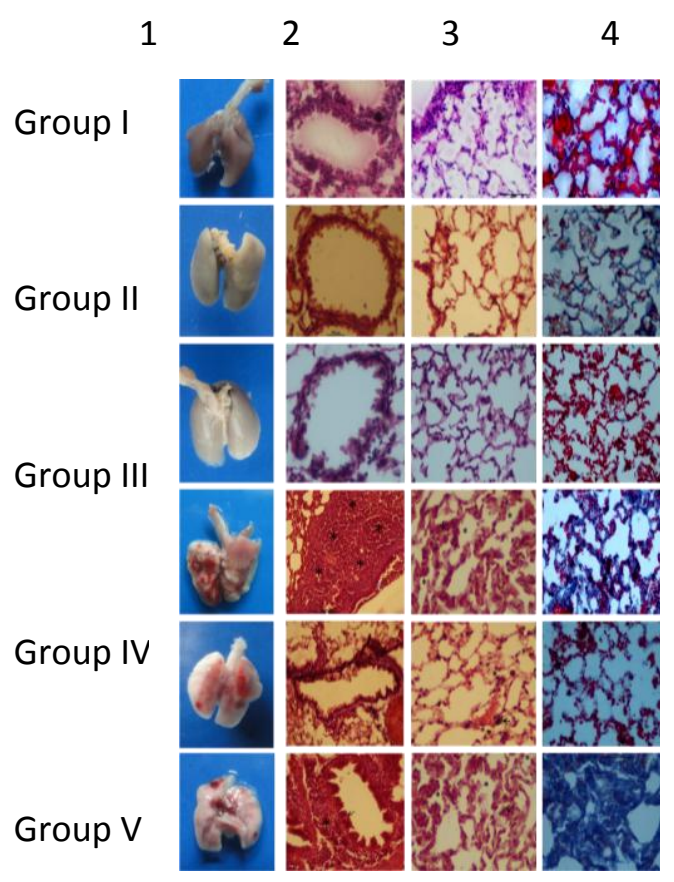

Fig. 1

In Group I, II and III (Control, tocopheryl acetate and soya bean oil treated mice respectively) showed normal histo-morphic structure of lung (fig.1).

Fig. 1: Group I control showing H\& E stain; 1 morphology of lung, 2 bronchus and 3 parenchyma with alveoli and $4 \mathrm{M}$ T stain fibres (blue). Group II (tocopheryl acetate induced) showing; 1 morphology of lung, 2 bronchus and 3 parenchyma with alveoli and 4 fibres (blue). Group III (soyabean oil induced used as vehicle for tocopheryl acetate) showing; 1 morphology of lung 2 bronchus and 3 parenchyma with alveoli and 4 fibres (blue). Group IV (Cigarette Smoke Expose) and VI (cigarette smoke expose plus soyabean oil used as control as vehicle for tocopheryl acetate used in group $\mathrm{V}$ ) showing H\& E stain; 1 morphology of lung with rough surface with varying size of nodules 2 bronchitis with multiple lymphatic nodule $\left({ }^{*}\right)$ and 3 parenchyma with alveoli collapsed with inflammatory cells infiltration and $4 \mathrm{M}$ T stain showing severity of presence of fibres (blue). Group V (tocopheryl acetate induced to cigarette smoke expose) showing few hematoma (1), reduced severity of bronchitis, few apoptotic cells and reduced presence of fibre by MT stain.

\section{Malondialdehyde (MDA) level}

The MDA level was found highest in cigarette smoke exposed groups(IV, VI) where MDA level in 
Group V (CSE plus Tocopheryl acetate treated) was found to be $570.5 \pm 56.32 \mu \mathrm{mol} / \mathrm{mg}$ protein (Table 1). cigarette smoke in the lung that can change antioxidant defense system leading to oxidative stress. This might have stimulated the body

Table 1: MDA level in control and treated adult mice by one way ANOVA, BMC test with $p>0.05$, $* * * p<0.0001$

\begin{tabular}{lccc}
\hline & $\begin{array}{c}\text { MDA level }(\mu \mathrm{mol} / \mathrm{mg} \text { protein }) \\
\text { Mean } \pm \text { SD }\end{array}$ & Group comparison & P -value \\
\hline Group I & $278.5 \pm 32.98$ & I Vs II & $>0.05$ \\
Group II & $279 \pm 52.05$ & I Vs III & $>0.05$ \\
Group III & $276.00 \pm 31.14$ & I Vs IV & $<0.0001$ \\
Group IV & $815.2 \pm 54.62^{* * *}$ & I Vs V & $<0.0001$ \\
Group V & $570.5 \pm 56.32^{* * *}$ & I Vs VI & $<0.0001$ \\
Group VI & $823.5 \pm 68.17^{* * *}$ & IVVs V & $<0.0001$ \\
& & IV Vs VI & $>0.05$ \\
\hline
\end{tabular}

On comparison of MDA level among different group by one way ANOVA, Bonferroni multiple comparison (BMC) test after CSE showed that Group I, II and III were insignificant ( $p>0.05)$ where as Group IV and VI increased significantly in comparison to Group I, $p<0.0001$ (Table 1). Group $\checkmark$ reduced significantly MDA level in response on administration of tocopheryl acetate to CSE mice in comparison to Group IV, $\mathrm{p}<0.001$ (Table 1).

\section{DISCUSSION}

Cigarette smoke is highly toxic to organ and their system. The obtained data showed cigarette smoke expose induces immune responsive and apoptosis in lung. In Present study, on gross examination of lung showed severely affected pathogenic with varying sizes of lymphatic nodular surface. Tobacco smoking also induced dosedependent increase in goblet cell formation and mucin secretory ability of rat airways ${ }^{11}$. Activation of neutrophils, in turn, released a number of mediators and proteases that spread the inflammatory response and contribute to the destruction of the lung airways ${ }^{12}$. Also, tobacco smoke has many toxic low molecular weight compounds that are able to directly stimulate bronchoalveolar dendritic cells (DCs). Activated DCs can discharge many of inflammatory chemokines that will induce the recruitment and activation of more DCs and other inflammatory cells such as neutrophils ${ }^{13}$. The pathogenic changes of lung consequenced due to its immune responsive on cigarette smoke and similar observation was found by other worker ${ }^{13-14}$. This observation may suggest effects of cigarettes smoke on the lung could be due to metabolites of immune system resulting to increase varying nodular in the lung due to immune responsive manifestation.On other hand, histological examination there were observed nodule around the pulmonary which could suggest that the mice may be resistant to lung tumor progression induced by cigarette smoke in present study. Further, histological examination, there were abundantly, present of collapse and reduction in alveoli, interstitial inflammation showing presence of lymphocytes, few degenerated apoptotic cells confirmed the tissue damage undergone due to chronic cigarette smoke expose in present study.

Present study, cigarette smoke expose to mice induced the biochemical impairment increasing the highest MDA level. This activity showed that reactive oxygen species such as hydroxyl, peroxyl contained in cigarette smoke via lipid peroxidation leading to cause an imbalance between cellular pro-oxidant and antioxidant levels leads to the oxidative stress resulting in tissue damage in lung. The antioxidant enzyme interacts directly with reactive oxygen species (ROS) to convert them to non-radical products. The overproduction of these radicals by cigarette smoking has an inhibitory effect on the enzymes responsible for removal of ROS such as superoxide dismutase, catalase and reduced glutathione ${ }^{15}$. In correlation with the alterations in enzymes activities, present data demonstrated an induction of inflammatory changes in tissues due to the effect of smoking exposure on rats. These abnormality changes involved an interstitial inflammation showed the presence of lymphocytes and plasma cells in lungs. All these inflammatory changes were significantly improved when the cigarette smoke-exposed 
albino mice were given tocopheryl acetate through oral gavage. It has been reported that prolonged smoking causes deficiencies in antioxidant enzyme activities of different tissues in mice ${ }^{16}$. This impairment was due to the inhibitory effects of ROS present in tobacco constituents on these enzymes.

It was shown that the long-term administration of tobacco smoking can impair the enzymatic antioxidant defense system of the mice lung. These alterations may be one of the responsible factors for smoking-induced inflammation in these $\operatorname{organs}^{17}$.

Long-term administration of cigarette smoke caused apoptosis in lung tissue and impaired the enzymatic antioxidants in liver. Such alterations may lead to the cigarette smoke induced inflammation in this organ. Kuo ${ }^{18}$ et al., demonstrated that the effect of CS-induced lung injury including apoptosis may be via reactive oxygen species and nitrogen oxides generation.

Protective role of tocopheryl acetate reacts at considerable rates with a variety of free radical species against cigarette smoke in present study can be explained by its antioxidant property.Tocopheryl acetate subsequently proved to be effective in preventing lipid peroxidation and other radical driven oxidative events ${ }^{8,9,19}$.

From present study, Lung tissue damage can be associated with pro oxidant increased level which resulted the oxidative stress. Tocopheryl acetate is an antioxidant, which fulfils the degraded antoxidant level due to increased level of malondialdehyde. Tocopheryl acetate administered may play a protective role against tissue damage due to cigarette smoke expose.

\section{Conflict of interest : None}

\section{REFERENCES}

1. World health organisation. (2015). WHO global report on trends in prevalence of tobacco smoking, 2015. Retrieved January 14, 2016, from http://apps.who.int/iris/bitstream/10665/156262/ 1/9789241564922_eng.pdf.

2. Leon ME, Peruga A, McNeill A, Kralikova E, Guha N, Minozzi $S$, et al. European Code against Cancer, 4th Edition: Tobacco and cancer. Cancer Epidemiology. 2015 Dec;39:S20-\$33. Available from: http://dx.doi.org/10.1016/j.canep.2015.06.001.

3. Church DF, Pryor WA. Free-radical chemistry of cigarette smoke and its toxicological implications. Environmental Health Perspectives. 1985 Dec 1;64:111-26. Available from: http://dx.doi.org/10.1289/ehp.8564111.
4. PRYOR WA, STONE K. Oxidants in Cigarette Smoke Radicals, Hydrogen Peroxide, Peroxynitrate, and Peroxynitrite. Annals of the New York Academy of Sciences. 1993 May;686(1 Tobacco Smoki):12-27. Available from: http://dx.doi.org/10.1111/j.17496632.1993.tb39148.x.

5. Rahman I, Li XY, Donaldson K, Harrison DJ, MacNee W. Glutathione homeostasis in alveolar epithelial cells in vitro and lung in vivo under oxidative stress. Am J Physiol 1995;269:L285-L292. Available from: https://www.ncbi.nlm.nih.gov/pubmed/7573460

6. Watanabe K, Eto K, Furuno K, Mori T, Kawasaki H, Gomita Y. Effect of cigarette smoke on lipid peroxidation and liver function tests in rats. Acta Med Okayama 1995; 49: 271-274. Available from: https://www.ncbi.nlm.nih.gov/pubmed/8585399

7. Ludwig PW, Hoidal JR. Alterations in leukocyte oxidative metabolism in cigarette smokers. Am Rev RespirDis 1992;126:977-980. Available from: https://www.ncbi.nlm.nih.gov/pubmed/6295222

8. Tappel AL. Vitamin $E$ as the Biological Lipid Antioxidant. Vitamins \& Hormones . 1962;493-510. Available from: http://dx.doi.org/10.1016/s00836729(08)60732-3

9. Burton $\mathrm{GW}$, Ingold KU. Vitamin E: application of the principles of physical organic chemistry to the exploration of its structure and function. Accounts of Chemical Research. 1986 Jul;19(7):194-201. Available from: http://dx.doi.org/10.1021/ar00127a001

10. Devasgayan TPA, Boloor KK, Ramasarma T. Methods of estimation of lipid peroxidation; an analysis of merits and demerits. Indian j Biophys. 2003; 40(5): 300-8. Available from: https://core.ac.uk/download/pdf/11616188.pdf

11. Stevenson CS. Characterization of cigarette smokeinduced inflammatory and mucus hypersecretory changes in rat lung and the role of CXCR2 ligands in mediating this effect. AJP: Lung Cellular and Molecular Physiology. 2005 Mar 1;288(3):L514L522. Available from: http://dx.doi.org/10.1152/ajplung.00317.2004.

12. Ind PW. COPD disease progression and airway inflammation: uncoupled by smoking cessation. European Respiratory Journal. 2005 Nov 1;26(5):764-6. Available from: http://dx.doi.org/10.1183/09031936.05.00102805.

13. Kantengwa S, Jornot L, Devenoges C, Nicod LP. Superoxide Anions Induce the Maturation of Human Dendritic Cells. American Journal of Respiratory and Critical Care Medicine. 2003 Feb;167(3):431-7. Available from: http://dx.doi.org/10.1164/rccm.200205-425oc.

14. P. C, A. P, T. L-W, G. N-D, W. K, E. F, et al. Morphological changes in lungs, placenta, liver and kidneys of pregnant rats exposed to cigarette smoke. International Archives of Occupational and Environmental Health. 2002 Jul 1;75(0):27-35. 
Available from: http://dx.doi.org/10.1007/s00420002-0343-3.

15. Santiago LN, de Camargo Fenley J, Braga LC, Cordeiro JA, Cury PM. The Effect of Different Doses of Cigarette Smoke in a Mouse Lung Tumor Model. International Journal of Clinical and Experimental Pathology. 2009;2(2):176-181. Available from: https://www.ncbi.nlm.nih.gov/pmc/articles/PMC25 83635/

16. Wajdy J, Al-Awaida, GM Abuereish and ZA Shraideh, 2013. Correlation of antioxidant and NADPH generating enzymes activities with tissues inflammation during smoke exposure of rats and smoke cessation. Res. Opin. Anim. Vet. Sci., 3(2), 41-49. Available from: http://www.roavs.com/pdffiles/Issue-2-2013/41-49.pdf
17. Avti PK. Smokeless Tobacco Impairs the Antioxidant Defense in Liver, Lung, and Kidney of Rats. Toxicological Sciences. 2006 Feb 1;89(2):547-53. Available from: http://dx.doi.org/10.1093/toxsci/kfj041.

18. Kuo W-H, Chen J-H, Lin H-H, Chen B-C, Hsu J-D, Wang C-J. Induction of apoptosis in the lung tissue from rats exposed to cigarette smoke involves p38/JNK MAPK pathway. Chemico-Biological Interactions. 2005 Jun;155(1-2):31-42. Available from: http://dx.doi.org/10.1016/j.cbi.2005.04.008.

19. Esterbauer $\mathrm{H}$, Dieber-Rotheneder $\mathrm{M}$, Striegl $\mathrm{G}$, and Waeg G. Role of vitamin $E$ in preventing the oxidation of low density lipoprotein. Am. J. Clin. Nutr. 1991;53, 314S-321S.Available from: http://ajcn.nutrition.org/content/53/1/314S.full.pd f+html. 